\title{
Pontine Maps Linking Somatosensory and Cerebellar Cortices Are in Register with Climbing Fiber Somatotopy
}

\author{
Francis Odeh, ${ }^{1 \star}$ Rochelle Ackerley, ${ }^{2 \star}$ Jan G. Bjaalie, ${ }^{1}$ and Richard Apps ${ }^{2}$ \\ ${ }^{1}$ Neural Systems and Graphics Computing Laboratory, Centre for Molecular Biology and Neuroscience, and Department of Anatomy, University of Oslo, \\ N-0317 Oslo, Norway, and 2Department of Physiology, School of Medical Sciences, University of Bristol, Bristol BS8 1TD, United Kingdom
}

The cerebropontocerebellar mossy fiber system is a major CNS sensorimotor pathway. We used a double-retrograde axonal tracing technique (red and green beads) to chart in rats the pontocerebellar projection to different electrophysiologically defined climbing fiber zones in the posterior lobe (face-receiving A2 zone and forelimb- and hindlimb-receiving parts of the $\mathrm{C} 1$ zone in the paramedian lobule and copula pyramidis, respectively). Individual cortical injection sites were verified as located in a given zone by mapping the pattern of cell labeling in the inferior olive, whereas labeled cells in the pontine nuclei were mapped using computer-aided three-dimensional reconstruction techniques. A number of topographical differences were found for the pontine projection to the individual zones. Projections to the $\mathrm{A} 2$ zone were bilateral, whereas to both parts of the $\mathrm{C} 1$ zone, the inputs were mainly contralateral. Furthermore, the $\mathrm{A} 2$ (face), $\mathrm{C} 1$ (forelimb), and C1 (hindlimb) zone projections were centered in progressively more caudal parts of the pontine nuclei with little or no overlap between them. The areas occupied by cell labeling for each zone corresponded closely to territories in the pontine nuclei shown previously to receive projections from somatotopically equivalent regions of the somatosensory cortex. This precise cerebropontocerebellar topography, defined by climbing fiber somatotopy, is a new principle of organization for linking somatosensory and cerebellar cortices. The convergence of direct and indirect sensory projections is likely to have important implications for cerebellar cortical processing.

Key words: cerebellum; inferior olive; pontine nuclei; cerebral cortex; primary somatosensory cortex; 3-D reconstruction; somatotopy

\section{Introduction}

The cerebropontocerebellar projection is one of the most substantial in the CNS, linking the cerebral cortex with the cerebellum, the largest sensorimotor structure in the mammalian brain. Any attempt to understand the mode of operation of this major brain pathway connecting sensory with motor circuits crucially benefits from knowledge of its topographical organization. However, despite numerous studies, there is no consensus on underlying principles of organization (cf. Brodal and Bjaalie, 1992, 1997; Schwarz and Thier, 1999). This may in part be because of the fact that in the primary somatosensory cortex (SI), different body parts are represented in a systematic manner, whereas in the cerebellar cortex, the arrangement is more complex.

On the one hand, studies of mossy fiber afferents to the cerebellum, which arise primarily from the pons, have failed to identify a clear topographical organization (Brodal and Bjaalie, 1992, 1997; Schwarz and Thier, 1995; Leergaard, 2003), and physiolog-

Received Feb. 10, 2005; revised April 5, 2005; accepted April 19, 2005

This work was funded in part by a Medical Research Council Senior Research Fellowship Award to R. Apps, the Research Council of Norway, and European Community Grant QLG3-CT-2001-02256 to J.G.B. We thank Trygve Leergaard and Christian Pettersen for valuable advice on the use of analytical software tools.

*F.0. and R.A. contributed equally to this work.

This article is linked to a web archive available at http://www.nesys.uio.no/Database. The archive contains supplementary illustrations and original coordinate files for downloading and reuse by other investigators.

Correspondence should be addressed to Dr. Richard Apps, Department of Physiology, School of Medical Sciences, University of Bristol, Bristol BS8 1TD, UK. E-mail: r.apps@bristol.ac.uk.

DOI:10.1523/JNEUROSCI.0558-05.2005

Copyright $\odot 2005$ Society for Neuroscience $\quad$ 0270-6474/05/255680-11\$15.00/0 ical studies suggest they produce an intricate mosaic of peripheral receptive fields within the cortex [the fractured somatotopy of Shambes et al. (1978)] (i.e., a discontinuous representation of different body parts). Tactile responses mediated by mossy fibers are thought to be generated by a combination of direct (trigeminocerebellar and spinocerebellar) and indirect (cerebrocerebellar) pathways (cf. Morissette and Bower, 1996). The latter involves the SI cortex and a relay within the pontine nuclei.

On the other hand, studies of the other major afferent to the cerebellum, the climbing fibers, have shown that these arise exclusively from the inferior olive, and specific olivary subnuclei provide climbing fibers that target parasagittally oriented zones of cerebellar cortical Purkinje cells (the sole output neurones of the cortex). Many regard these zones as fundamental to cerebellar information processing (Voogd and Glickstein, 1998; Apps and Garwicz, 2005). Climbing fibers also impose a degree of somatotopical order within the cerebellar cortex. For example, from medial to lateral in the paramedian lobule of the rat cerebellum, a face-receiving A2 zone is present followed by a forelimbreceiving $\mathrm{C} 1$ zone, whereas farther caudally in the copula pyramidis, the $\mathrm{C} 1$ zone is mainly a hindlimb-receiving area (Atkins and Apps, 1997; Pardoe and Apps, 2002). This arrangement holds true in a number of species, suggesting that it is a key feature underlying cerebellar contributions to movement control.

To date, most anatomical studies of cerebellar inputs have considered either the mossy fiber or climbing fiber projections in isolation, and an important gap in our knowledge is how the 
spatial organization of cells within the pontine nuclei providing mossy fiber inputs to the cerebellar cortex are organized in relation to climbing fiber cortical zones.

In the present study, we provide evidence that a precise topographical organization is present in the pontocerebellar projection, which relates to climbing fiber somatotopy. This organization appears to preserve the relationship between different parts of the SI cortex and somatotopically equivalent regions in the cerebellar cortex. Thus, we are able to reveal a new principle that may underlie the way in which the somatosensory and cerebellar cortices are linked.

\section{Materials and Methods}

Surgical procedures. All experimental procedures were performed in accordance with the United Kingdom Animals Scientific Procedures Act (1986) and were approved by the institutional animal license advisory group. Results were obtained from a total of eight adult rats (three female Sprague Dawley rats, 230-235 g, and five male Wistar rats, 260-285 g). Six animals were anesthetized with sodium pentobarbitone $(50 \mathrm{mg} / \mathrm{kg}$, i.p.; Sagatal; Rhone Merieux, Harlow, UK), and supplementary doses were given as required to maintain surgical levels of anesthesia. The remaining two (Sprague Dawley) animals were sedated with fentanylfluanisone (0.4 ml/kg, i.m.; Hypnorm, High Wycombe, UK) and then anesthetized using Propofol (Rapinovet; Schering-Plough, Welwyn Garden City, UK) through a continuous intravenous pump (flow rate variable between 0.006 and $0.05 \mathrm{ml} / \mathrm{min}$ ) via a cannula inserted into a tail vein. In all cases, a sufficient level of surgical anesthesia was determined by regular testing of leg withdrawal and corneal reflexes. Atropine sulfate (0.6 mg/kg, s.c.; Atrocare; Animalcare Ltd., Dunnington, UK) was administered to reduce secretions, as required.

The rats were placed in a stereotaxic frame, and their rectal temperature was monitored and maintained within physiological limits with a thermostatically controlled heated blanket. A small craniotomy exposed the dorsal surface of the posterior lobe of the cerebellum, allowing access to the medial part of the paramedian lobule (PML) and copula pyramidis (CP) on one side of the cerebellum. The dura was removed, and the cerebellar cortex was periodically flushed with saline.

Electrophysiological stimulation and recording. In each animal, cortical zones in the medial aspect of the PML and CP were mapped electrophysiologically by recording the mediolateral sequence of climbing fiber field potentials evoked by ipsilateral forelimb or hindlimb, or contralateral face stimulation, as described previously (Atkins and Apps, 1997; Teune et al., 1998; Pardoe and Apps, 2002). In brief, percutaneous electrical stimulation was applied (single pulse; $0.1 \mathrm{~ms}$ duration) once every $1.5 \mathrm{~s}$ at an intensity to evoke a small but visible twitch in the body region stimulated. The evoked climbing fiber field potentials were recorded extracellularly from the surface of the PML and $\mathrm{CP}$, using tungsten-in-glass microelectrodes (tip diameter, $\sim 50 \mu \mathrm{m}$ ). As in previous studies (Atkins and Apps, 1997), each cortical zone was defined in terms of the peripheral stimulation site that evoked the largest climbing fiber responses within that zone. Hereafter, these are termed the A2-face, C1-forelimb, and C1-hindlimb zones. The responses were recorded differentially, amplified, and bandpass filtered ( $30 \mathrm{~Hz}$ to $5 \mathrm{kHz}$ ), and a Humbug device (Quest Scientific, North Vancouver, British Columbia, Canada) was used to eliminate any $50 \mathrm{~Hz}$ electrical interference. Responses were recorded from individual cerebellar sites separated in the mediolateral axis by intervals of $0.1-0.2 \mathrm{~mm}$. Data from each site were digitized on-line (sampling rate, $2.5 \mathrm{kHz}$ ) using a Cambridge Electronic Design (Cambridge, UK) 1401 analog-to-digital converter and customized triggersampled software (Spike 2; Cambridge Electronic Design).

Tracer injections and tissue preparation. Individual microinjections of axonal tracer were made into the cerebellar cortex, in which the largest climbing fiber responses were evoked by the peripheral stimulation (see Fig. 1). This usually corresponded to the approximate center of a given climbing fiber zone (cf. Atkins and Apps, 1997; Teune et al., 1998; Pardoe and Apps, 2002). Retrograde tracer material (50 nl; green or red beads; Lumafluor, New City, NY) was delivered hydraulically via a glass micropipette (tip diameter, $\sim 20 \mu \mathrm{m}$ ) attached to a $1 \mu$ l Hamilton syringe
(Precision Sampling, Baton Rouge, LA). Each microinjection was made at a depth of $0.3-0.4 \mathrm{~mm}$, perpendicular to the pial surface of the cerebellum. In all eight animals, a microinjection of red beads was made into one cortical zone and a microinjection of green beads into another, thereby generating a total of 16 cases (for details, see Table 1). After the injections were made, the surface of the cerebellum was rinsed with saline, the exposure was covered with Gelfoam, the wound was closed in layers, and the animals were allowed to recover. As a precautionary measure, analgesia was maintained postoperatively for $\sim 24 \mathrm{~h}(0.1 \mathrm{mg} / \mathrm{kg}$, s.c.; buprenorphine; Temgesic; Schering-Plough).

After a $7-10 \mathrm{~d}$ survival period for axonal transport of tracer to occur, the rats were deeply reanesthetized using sodium pentobarbitone (60 $\mathrm{mg} / \mathrm{kg}$, i.p.; Sagatal; Rhone Merieux) and then transcardially perfusion fixed with a heparinized saline flush ( $\sim 500 \mathrm{ml} ; 0.9 \%$ saline $)$, immediately followed by fixative ( $\sim 500-750 \mathrm{ml} ; 4 \%$ paraformaldehyde in phosphate buffer), and finally a sucrose PBS solution ( $\sim 500 \mathrm{ml} ; 10 \%$ sucrose). The cerebellum and underlying brainstem were carefully removed, stored at $4^{\circ} \mathrm{C}$, and left to sink in $30 \%$ sucrose PBS, until sectioned on a freezing microtome. Before sectioning, the brainstem was divided into a pontine and an olivary block, and each block was sectioned transversely at $50 \mu \mathrm{m}$ and mounted serially. One complete series of sections was mounted from the pontine block, whereas the olive sections were mounted as two separate series: one for analysis and the other as a spare. The cerebellum was sectioned sagittally at 100 or $50 \mu \mathrm{m}$ (one animal) and mounted serially.

Mapping of injection sites and olive cell labeling. The cerebellar and olivary sections were examined using a Leica (Wetzlar, Germany) DMRB fluorescent microscope, with the sections temporarily coverslipped with PBS. Green fluorescent labeling was viewed with an H3 filter block [dichroic mirror (DM), $510 \mathrm{~nm}$; bandpass (BP), 420-490 nm; long-pass (LP), $520 \mathrm{~nm}$ ], and red fluorescent labeling was viewed with an N2.1 filter block (DM, $580 \mathrm{~nm}$; BP, 515-560 nm; LP, $580 \mathrm{~nm}$ ). In each case, the cerebellar injection site was defined as the intense core of fluorescence resulting from residual tracer material at the site of injection. Two measurements were taken of this core to provide an estimate of injection site size: (1) the maximum mediolateral width of the core and (2) in each section containing the core, the rostrocaudal length of the white matter/ granular layer interface occupied by the core. These length values were then summed, and the total was multiplied by the section interval to obtain an estimate of injection site area (cf. King et al., 1998; Pardoe and Apps, 2002). The one exception was a case in which the injection site was too shallow to reach the white matter/granular layer interface. In this case, only the mediolateral width of the injection site was determined.

To illustrate the relationship between the histologically defined mediolateral spread of each injection site and the electrophysiologically defined mediolateral width of each cortical zone, a scale diagram was constructed for each case (termed a figurine). The extent of each injection site in the mediolateral plane was depicted as a solid bar sitting on a horizontal line (see Fig. 3). The solid bar was placed on the line in relation to the zonal boundaries as deduced electrophysiologically for that case (i.e., the mediolateral width of the zone equals the length of the horizontal line). The width of the zone was also depicted by the length of an arrow below the line.

As an independent evaluation of the extent to which individual injection sites were confined within the mediolateral boundaries of a given cerebellar cortical zone, the spatial distribution of retrogradely labeled cells in one series of sections of the contralateral inferior olive was also plotted onto standard horizontal maps [based on transverse outlines constructed by Apps (1990)].

Mapping of pontine labeling. The term pontine nuclei is defined here as the group of nuclei ventral to and partly surrounding the descending fiber tract at the level of the pons (basilar pontine nucleus, not including the nucleus reticularis tegmenti pontis). The spatial distributions of retrogradely labeled cells within the pontine nuclei were recorded using an image-combining microscope running the Neurolucida (MicroBrightField, Williston, VT) three-dimensional (3-D) reconstruction system based on a Zeiss (Oberkochen, Germany) Axioskop II Mot microscope equipped with a Märzhäuser motorized stage (Märzhäuser GmbH \& Co. KG, Wetzlar-Steindorf, Germany). A Zeiss filter set no. 15 (DM, $580 \mathrm{~nm}$; $\mathrm{BP}, 546 / 12 \mathrm{~nm}$; LP, $590 \mathrm{~nm}$ ) was used to visualize cells retrogradely 
labeled with red beads, and filter set no. 09 (DM, $510 \mathrm{~nm}$; BP, 450-490 $\mathrm{nm}$; LP, $515 \mathrm{~nm}$ ) was used to visualize cells labeled with green beads. Every labeled cell in alternate sections through the entire rostrocaudal extent of the pontine nuclei was plotted on the Neurolucida system as individual points, and each point was registered as being a single-labeled red or green cell, and if it was double-labeled, an additional tag was given. Major anatomical landmarks and boundaries (the ventral pontine surface, the outline of the left and right pontine gray, the outline of the left and right peduncles, the midline and fourth ventricle) were coded as lines. For every case, the cell counts were performed independently by two investigators, and there was good correspondence between the two sets of values obtained (there was no significant difference between the two sets of total cell counts; Student's paired $t$ test, $p=0.65$; correlation coefficient, $r=0.94)$.

Data from the Neurolucida system were transferred to Silicon Graphics Octane 2 workstations, running program Micro3D (Neural Systems and Graphics Computing Laboratory, University of Oslo; http:// www.nesys.uio.no/Database). This software was used for 3-D reconstruction, visualization, and analysis of the distribution of retrogradely labeled pontine cells to facilitate understanding of spatial relationships and to aid comparison of data obtained in different animals (cf. Leergaard et al., 2000a,b; Brevik et al., 2001). The digitized sections were assigned $z$-values defined by section thickness and serial order and then aligned interactively on a computer screen with the aid of the anatomical landmarks listed above. To assist the alignment, the 3 -D reconstructions were inspected from different angles of view using real-time rotation. After alignment, a local pontine coordinate system, defined by Brevik et al. (2001), was applied to each reconstruction (see Fig. 2) with the use of affine transformations (Ashburner and Friston, 1999). This uses a cuboid bounding box, oriented along the long axis of the brainstem at the level of the pons, with its boundaries adjusted to fit the histologically defined rostrocaudal, mediolateral, and dorsoventral limits of the pontine nuclei. The ventral surface of the peduncles was also used as an internal landmark (for additional details, see Brevik et al., 2001). The origin of the coordinate system was defined as the intersection of the three planes formed by the medial and rostral sides of the bounding box and the plane halfway between its ventral and dorsal sides. Relative coordinates within the pontine nuclei were defined from rostral $(0 \%)$ to caudal $(100 \%)$, from medial ( $0 \%$ ) to lateral (100\%), and from "central" (the horizontal plane halfway from ventral to dorsal) to ventral (100\%) and dorsal $(-100 \%)$.

As in previous studies (for example, see Leergaard et al., 2000a), the distributions of labeled cells in the pontine nuclei for each case were shown as dot maps in the pontine coordinate system displayed in three different angles of view (see Fig. 2; the data were also resliced in multiple user-defined section planes for detailed visual analyses; see http:// www.nesys.uio.no/Database for additional details). Datasets from individual cases were pooled (see Fig. $4 A, C, E$ ) to compare the overall distribution of labeled pontine cells projecting to specific cerebellar cortical zones. The pooled data for each of the three cortical zones were also compared with maps showing the distributions of selected cerebropontine terminal projection fields as viewed in the same pontine coordinate system.

The cerebropontine results were obtained from a data archive at http://www.nesys.uio.no/Database [introduced and analyzed previously for another purpose by Leergaard et al. (2000a)]. The archive contains cerebropontine data based on anterograde tracer injections made into different electrophysiologically identified locations within SI cortex. Cases were selected from the database in which injections were made into regions receiving sensory input from the corresponding body parts that provided climbing fiber input to the cerebellar cortical zones under investigation (see Fig. 4B, D,F). A novel application (J. O. Nygaard, S. Gaure, C. Pettersen, H. Avlesen, and J. G. Bjaalie; see http:/www.nesys. uio.no/ttp) based on Java 3-D (Sun Microsystems, Santa Clara, CA) was used to create envelopes, representing isodensity surfaces, surrounding the point clusters from both the pooled distributions of labeled pontocerebellar cells and the distributions of labeled SI cerebropontine terminals (see Fig. 5). The application creates scalar fields from the data by binning of the point coordinates. For a given point cloud, this nonparametric estimation is performed to obtain a probability density function $f$, modeling the distribution of points. Normalizing $f$ to the range $[0,1]$, a parametric family of isosurfaces of $f$ is created. The user then chooses a specific isodensity surface that surrounds the main clusters of points and excludes the points in the low-density regions at the periphery of the clusters (see Results).

\section{Results}

\section{Evaluation of cases}

Microinjections of tracer material were made into the cerebellar cortex in three Sprague Dawley and five Wistar rats, providing a total of 16 different injection sites (cases). Because the results obtained in both strains of rat were very similar, the data are considered together. The locations of microinjections were determined by charting on the cerebellar surface climbing fiber field potentials evoked by peripheral stimulation (see Materials and Methods). In each case, the injection was made into approximately the center of (1) the C1-forelimb zone in PML ( $n=6$ cases), (2) the C1-hindlimb zone in CP ( $n=3$ cases), or (3) the A2-face zone in PML ( $n=7$ cases).

The present report is confined, however, to consideration of results obtained from a total of nine cases obtained from seven animals in which the following two criteria were satisfied. First, that the injection site in each case did not encroach significantly into the white matter (Fig. 1, example photomicrographs of injection sites and the appearance of retrograde cell labeling in the pons). Second, that most $(>94 \%)$ of the territory occupied by retrogradely labeled cells in the contralateral inferior olive was located within parts of the olive known to provide climbing fibers to the particular cortical zone under study (Table 1) (cf. Apps, 1990; Atkins and Apps, 1997; Pardoe and Apps, 2002). In all but one of the nine cases that fulfilled these criteria, it was also possible to confirm that the histologically defined mediolateral width of the injection site was within the limits of the zone as defined electrophysiologically (i.e., the core of the injection site was within a region of cortex in which climbing fiber field responses were recorded consistent with that zone). In the one additional case (case BR05), only limited physiology was performed to identify the approximate center of the zone. In this case, $94.4 \%$ of the retrograde cell labeling in the contralateral inferior olive was within the "appropriate" territory for the targeted zone. We therefore conclude that in all nine cases selected for detailed analysis, the cerebellar cortical injection site was mainly (in many cases probably exclusively) limited to within the mediolateral boundaries of the climbing fiber-defined cerebellar cortical zone under investigation.

In the present experiments, an additional and important consideration is the area of effective uptake and retrograde transport of tracer material from the cortical injection site. If the area of tracer uptake is similar for both climbing fiber and mossy fiber afferents, it should follow that, in each case, the numbers of cells retrogradely labeled with red or green beads in the inferior olive are positively correlated with the corresponding cell counts in the pontine nuclei. In the present experiments, there was a statistically highly significant positive correlation between the olive and the pontine cell counts $(r=0.77 ; p<0.001 ; n=16)$, implying that the effective injection site was similar for both types of cerebellar afferent. Note, however, that it is not possible with the retrograde tracing method used to determine the number of mossy fiber terminal branches that any one labeled pontine cell provides to the cerebellar cortical area under study.

\section{Cell labeling in the pontine nuclei}

The distributions of cell labeling in the pontine nuclei, originating from the nine restricted injection sites, were reconstructed in 

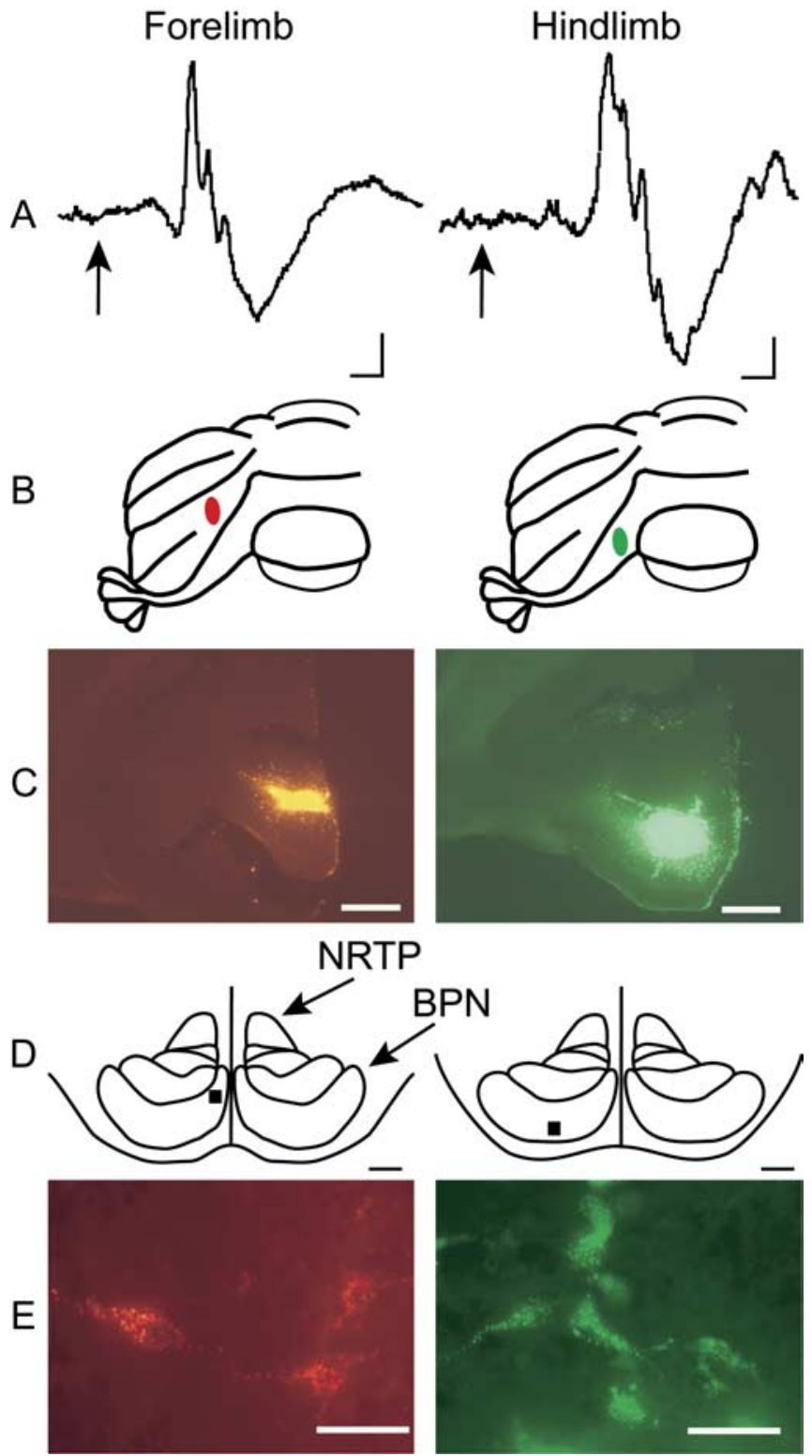

Figure 1. Example physiological responses and anatomical labeling (experiment BR14). $\boldsymbol{A}$, Evoked climbing fiber field potentials recorded on the cerebellar cortical surface at approximately the center of the C1-forelimb zone in the paramedian lobule (left) and the C1-hindlimb zone in the copula pyramidis (right). In each case, there was an average of $n=4$ sweeps; the arrow indicates time of peripheral stimulation. Calibration: $5 \mathrm{~ms}, 0.1$ and $0.05 \mathrm{mV}$ for forelimb and hindlimb responses, respectively. $\boldsymbol{B}$, Posterior view of the rat cerebellum showing the approximate location of the injections of tracer into each zone. $C$, Photomicrographs of sagittal sections of the cerebellum showing the core of the two injection sites. $\boldsymbol{D}$, Camera lucida drawing of a transverse section through the pontine nuclei (approximately $-8 \mathrm{~mm}$ to bregma). Boxes indicate locations of high-power photomicrographs in $\boldsymbol{E}$, which show examples of retrogradely labeled cells in the pontine nuclei; all labeled cells were multipolar and of similar shape and size. Scale bars: $\boldsymbol{C}, 500 \mu \mathrm{m} ; \boldsymbol{D}, 200 \mu \mathrm{m} ; \boldsymbol{E}, 20 \mu \mathrm{m}$. NRTP, Nucleus reticularis tegmenti pontis; BPN, basilar pontine nucleus.

3-D and transferred to the local pontine coordinate system (Fig. 2) (for additional details, see Materials and Methods) (Leergaard et al., 2000a,b; Brevik et al., 2001). In two animals (BR13 and $\mathrm{BR} 14)$, it was possible to directly compare the spatial distributions of pontine cell labeling arising from injections centered on two different cortical zones in the same animal (the C1-forelimb zone compared with the C1-hindlimb zone in animal BR14 and the A2-face zone compared with the C1-hindlimb zone in animal
BR13). In both of these double-tracer experiments, there was no overlap in the distributions of the two populations of singlelabeled cells in the contralateral inferior olive, and no doublelabeled olive cells were found. Thus, we conclude that in both pairs of cases, the two injection sites did not spread to involve the other cortical zone.

Figure 2 shows the pontine data from one of these doubletracer experiments, plotted in the local pontine coordinate system. The two single-labeled cell populations are shown in 3-D reconstructions, using three different angles of view: ventral, medial, and rostral (Fig. 2C-E, respectively). The view from ventral shows the overall distribution to advantage, whereas the other views help define the shape of the cell groups and their dorsoventral distribution. Inspection of Figure 2 shows a difference in the topographical distribution of the two populations of singlelabeled cells on the contralateral side of the pons, which is most evident when displayed in the ventral angle of view (Fig. 2C). Cells retrogradely labeled after the $\mathrm{C} 1$-hindlimb zone injection (green labeling) are mainly located within the caudal aspect of the pontine nuclei, whereas cells retrogradely labeled after the C1forelimb zone injection (red labeling) are located adjacent and rostral to the C1-hindlimb zone cell group.

In the second double tracer experiment (BR13), the pontine cells labeled after a C1-hindlimb zone injection occupied a very similar caudal location as the corresponding cell group in experiment BR14, whereas the pontine cells labeled from the injection into the A2-face zone were located more rostrally, occupying the central aspect of the contralateral pontine nuclei, with very little overlap with the other population of single-labeled cells. In both double-tracer experiments, no double-labeled cells were found.

The double-tracer results therefore provide strong evidence to suggest that topographically distinct regions of the pontine nuclei provide mossy fiber projections to different zones of cerebellar cortex defined by the somatotopy of their climbing fiber input. These findings also suggest that it would be of value to compare the distributions of cell labeling from individual cases obtained in different animals, using the local pontine coordinate system to normalize the data.

Individual cases, representative of the material as a whole, are shown in Figure 3. In each example, the injection was centered either on the A2-face zone (Fig. $3 A, B$ ), the $\mathrm{C} 1$-forelimb zone (Fig. $3 C, D$ ), or the $C 1$-hindlimb zone (Fig. $3 E, F$ ). In each case, the pattern of cell labeling in the contralateral inferior olive was restricted to the territory known to provide climbing fibers to that particular zone (for the A2-face zone, Fig. 3A: subnucleus $\mathrm{b}^{1}$ of the caudal medial accessory olive and the ventral lateral outgrowth; for the $\mathrm{C} 1$-forelimb zone, Fig. 3C: the rostral dorsal accessory olive and mid/rostral parts of the medial accessory olive; and for the C1-hindlimb zone, Fig. 3E: rostrolateral parts of the dorsal accessory olive) (cf. Apps, 1990; Atkins and Apps, 1997; Pardoe and Apps, 2002). The figurine below each olive map also shows that in each case the histologically defined width of the injection site was smaller than the corresponding width of the zone defined electrophysiologically (see Materials and Methods for additional details). Thus, in each case, the injection site was most probably confined to the climbing fiber zone under study.

For the three cases, the ventral angle of view of the pons displayed the essential topographical differences between them in terms of spatial distribution of cell labeling in the pontine nuclei. Figure $3 B$ shows that the pattern of retrograde cell labeling arising from an injection into the A2-face zone was distributed bilaterally, approximately in the center of the pontine nuclei on each side, but with a slight bias to the contralateral side (on average, 
Table 1. Summary of cases

\begin{tabular}{|c|c|c|c|c|c|c|}
\hline Case & Zone injected $^{a}$ & Tracer color & Injection site area $\left(\mathrm{mm}^{2}\right)$ & Percentage olive cells ${ }^{b}$ & Physiology & 3-D reconstruction \\
\hline \multirow[t]{2}{*}{ BR03 } & A2-face & Red & - & 66.4 & - & - \\
\hline & $\mathrm{C} 1-\mathrm{FL}$ & Green & 0.066 & 100 & + & $\sqrt{ }$ \\
\hline \multirow[t]{2}{*}{ BR05 } & A2-face & Green & 0.082 & 94.4 & - & $\sqrt{ }$ \\
\hline & $\mathrm{C} 1-\mathrm{FL}$ & Red & - & 87.4 & - & - \\
\hline \multirow[t]{2}{*}{ BR06 } & A2-face & Green & - & 88.6 & - & - \\
\hline & $\mathrm{C} 1-\mathrm{FL}$ & Red & 0.007 & 98.6 & + & $\sqrt{ }$ \\
\hline \multirow[t]{2}{*}{ BR12 } & A2-face & Green & - & 85.7 & - & - \\
\hline & $\mathrm{C} 1-\mathrm{FL}$ & Red & - & 77.1 & - & - \\
\hline \multirow[t]{2}{*}{ BR13 } & A2-face & Red & 0.017 & 100 & + & $\sqrt{ }$ \\
\hline & $\mathrm{C} 1-\mathrm{HL}$ & Green & 0.004 & 100 & + & $\sqrt{ }$ \\
\hline \multirow[t]{2}{*}{ BR14 } & $\mathrm{C} 1-\mathrm{FL}$ & Red & 0.041 & 100 & + & $\sqrt{ }$ \\
\hline & C1-HL & Green & 0.125 & 100 & + & $\sqrt{ }$ \\
\hline \multirow[t]{2}{*}{ BR15 } & A2-face & Green & 0.040 & 94.7 & + & $\sqrt{ }$ \\
\hline & $\mathrm{C} 1-\mathrm{FL}$ & Red & - & 40.6 & - & - \\
\hline \multirow[t]{2}{*}{ BR16 } & A2-face & Red & - & 47.6 & - & - \\
\hline & $\mathrm{C} 1-\mathrm{HL}$ & Green & 0.094 & 100 & - & $\sqrt{ }$ \\
\hline
\end{tabular}

+ , Histologically defined mediolateral width of the injection site was less than the mediolateral width of the zone defined physiologically; - , information not available; $\sqrt{ }$, analysis included 3-D reconstruction.

${ }^{a}$ Tracer injection centered on climbing fiber defined zone. FL, Forelimb; $\mathrm{HL}$, hindlimb.

${ }^{b}$ Percentage of total count of retrogradely labeled olive cells within olive territory for selected zone.

$54.5 \%$ of the labeled pontine cells arising from injections into the A2-face zone were contralateral to the cerebellar injection site; $n=3$ cases). Figure $3 D$ shows that the pattern of retrograde cell labeling in the pontine nuclei arising from an injection into the $\mathrm{C} 1$-forelimb zone was predominantly in the contralateral pons and was centered farther caudally (on average, $86.7 \%$ of the labeled pontine cells arising from injections into the $\mathrm{C} 1$-forelimb zone were contralateral to the cerebellar injection site; $n=3$ cases). Finally, Figure $3 F$ shows that the pattern of retrograde cell labeling arising from an injection into the C1-hindlimb zone was located overwhelmingly in the contralateral pons (on average, $96.5 \%$ of the labeled pontine cells arising from injections into the $\mathrm{C} 1$ hindlimb zone were contralateral to the cerebellar injection site; $n=3$ cases) and was located in the caudal-most third of the pons.

The individual cases therefore highlight a number of topographical differences between the pontocerebellar projections to each of the three cerebellar cortical zones. When the results are considered in the sequence A2-face, C1-forelimb, and C1-hindlimb, there is a progressive change from a bilateral to an almost entirely contralateral projection from the pontine nuclei, and the center of gravity of the cell labeling is shifted into progressively more caudal parts of the contralateral pons. These differences are amply confirmed when all the cell labeling from cases in which an injection was centered in a given zone are pooled and displayed as a merged plot in the local pontine coordinate system (Fig. 4A, C,E). Comparison with the equivalent cell distributions for individual cases plotted in Figure 3 shows a good correspondence: the overall

C

E
A
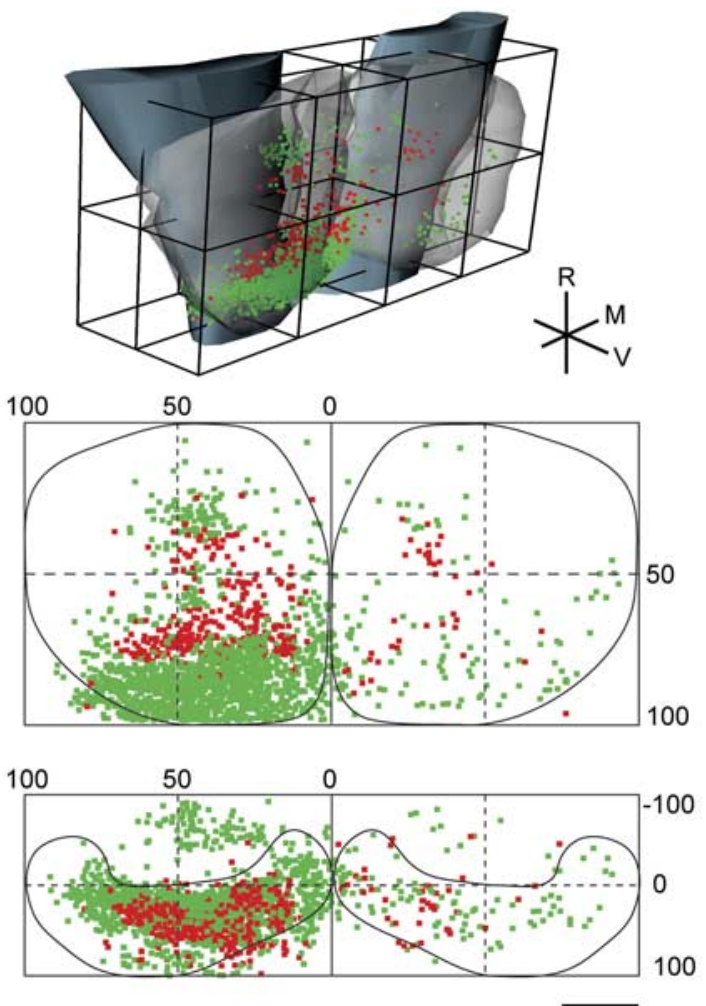

Figure 2. Computer-generated 3-D reconstruction of experiment BR14. An injection of red beads was made into the C1-forelimb zone in the paramedian lobule, and an injection of green beads was also made into the C1-hindlimb zone in the copula pyramidis. $\boldsymbol{A}$, Three-dimensional representation of the pons and its local coordinate system. Descending peduncles are shown as solid surfaces, boundaries of pontine nuclei are shown as transparent surfaces, and retrogradely labeled cells (red or green) are shown as dots inside surfaces. $\boldsymbol{B}$, Ventral view of rat caudal brainstem showing the position of the coordinate system and the region reconstructed. $\boldsymbol{C}-\boldsymbol{E}$, Topography of labeled pontocerebellar cells within the pons displayed in ventral $(V ; \boldsymbol{C})$, medial $(M ; \boldsymbol{D})$, and rostral $(\mathrm{R} ; \boldsymbol{E})$ views. See Materials and Methods for additional details. $\boldsymbol{F}$, Approximate position of injection sites indicated in a posterior view of the cerebellum. IPF, Interpeduncular fossa; $c p$, cerebral peduncle; py, pyramidal tract. Scale bar: (in $\boldsymbol{E}) \boldsymbol{C}-\boldsymbol{E}, 500 \mu \mathrm{m}$.
B

D

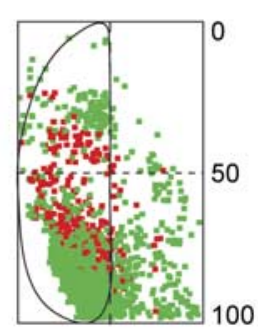

F

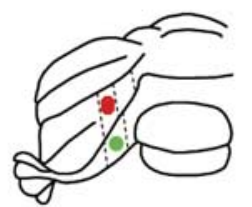

distribution of labeled cells in each pooled map does not greatly exceed the territory occupied in individual cases, implying considerable similarities in distribution among cases. This suggests that the pontocerebellar projection to each of the different cortical zones is quite homogeneous. 

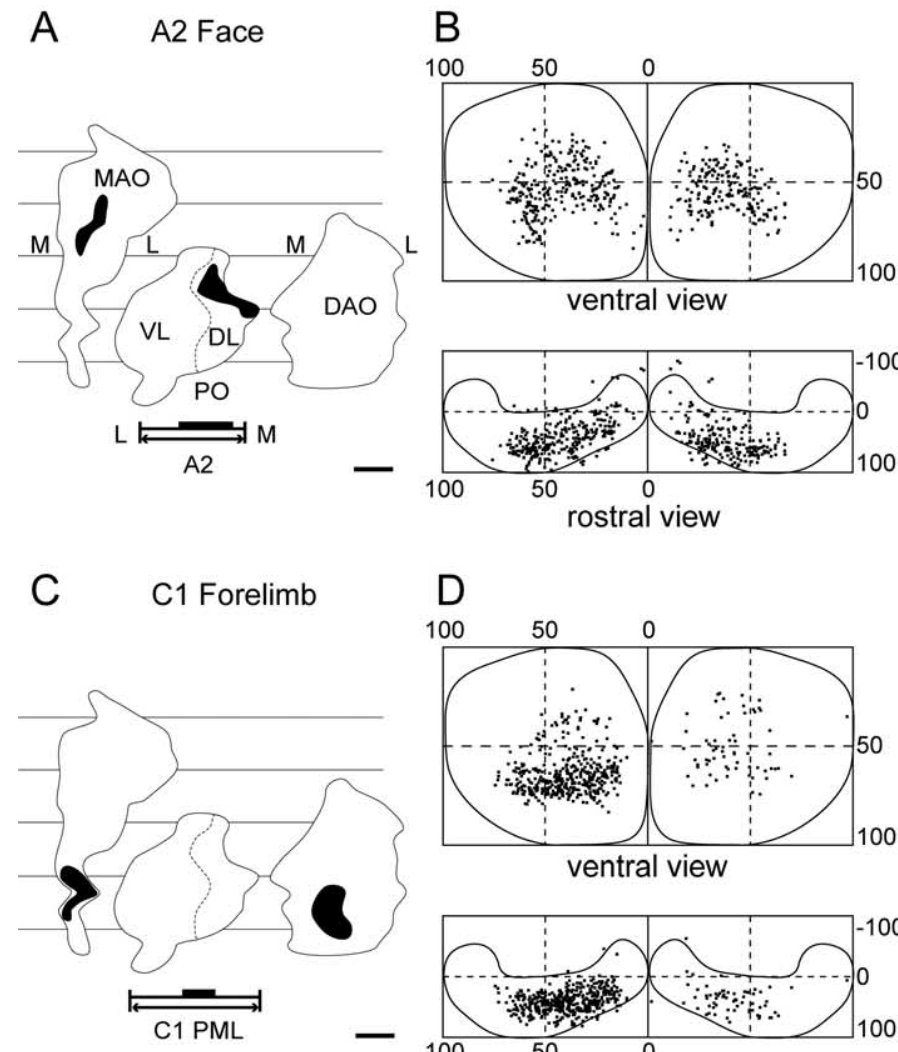

D
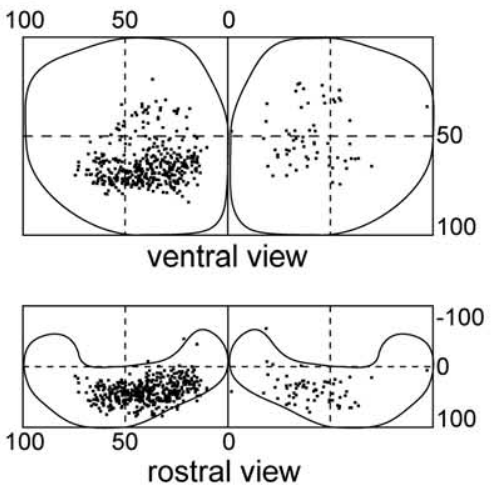

E C1 Hindlimb

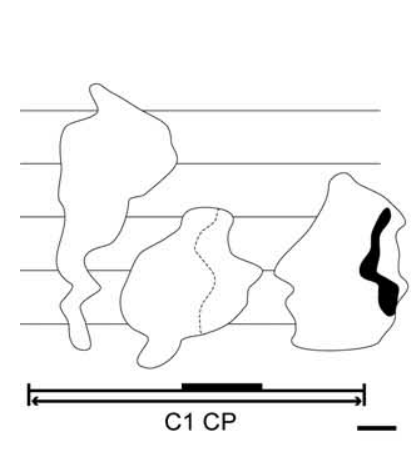

$\mathrm{F}$

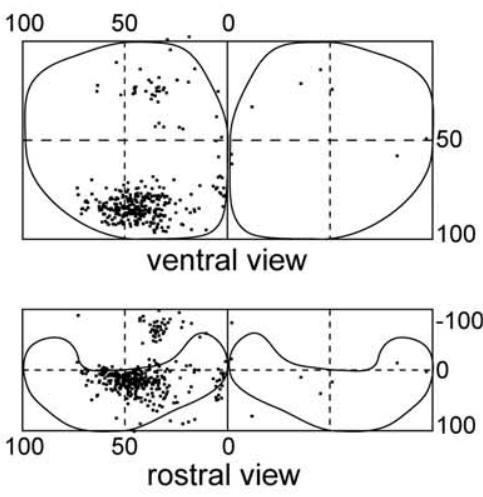

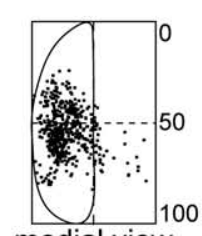

medial view

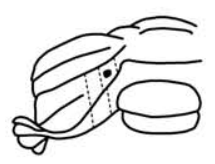

injection site
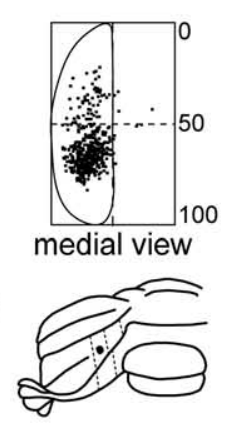

injection site
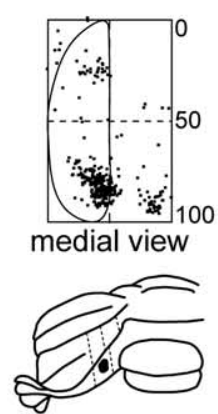

injection site

Figure 3. Olive and pontine cell labeling in three individual cases. $\boldsymbol{A}, \boldsymbol{B}, \mathrm{A2}$-face (case BR15); $\boldsymbol{C}, \boldsymbol{D}, \boldsymbol{C} 1$-forelimb (case BR06); $\boldsymbol{E}$, $F,(1-$ hindlimb (case BR16). $A, C, E$, Standard horizontal maps of the right inferior olive with filled areas indicating the location of retrogradely labeled cells. The pattern of cell labeling was consistent with the known topography of olivary inputs to the zones under investigation (see Results for additional details). The figurine below each olive map depicts the electrophysiologically defined mediolateral width of the zone (arrows) and the mediolateral spread of the injection site (black bar; see Materials and Methods for additional details). $\boldsymbol{B}, \boldsymbol{D}, \boldsymbol{F}$, Standard maps of left and right pontine nuclei constructed within the local coordinate system and presented in three angles of view: ventral, medial, and rostral. Each dot indicates a retrogradely labeled cell. In each case, the approximate location of the injection site is indicated on a posterior view of the left side of the cerebellum. DL, Dorsal lamella of PO; DAO, dorsal accessory olive; $\mathrm{MAO}$, medial accessory olive; $\mathrm{PO}$, principal olive; $\mathrm{VL}$, ventral lamella of $\mathrm{PO} ; \mathrm{M}$, medial; $\mathrm{L}$, lateral. Scale bars, $500 \mu \mathrm{m}$ for inferior olive and pontine nuclei; $200 \mu \mathrm{m}$ for injection site figurine.

For the seven additional cases not included in the detailed analysis (because the olive cell labeling indicated spread of injectate to neighboring zones), the overall distribution of cell labeling in the pontine nuclei was similar to the pattern that arises when the cell labeling from corresponding injections confined to individual zones was combined.

To obtain a better visualization of spatial relationships and obtain a more quantitative measure of the degree of spatial seg- regation between the different cell distributions, we used computer-generated geometric modeling with isodensity surfaces to display the outer boundaries of the pooled distributions of cell labeling targeting each of the three cortical zones (Fig. 5). This analysis is confined to consideration of the contralateral pontine nuclei, because the cell labeling was mainly on this side of the brain. In Figure 5, each 3-D shape is viewed from the ventral angle. The surface of each of the shapes surrounds regions containing high to medium density cell labeling, whereas regions containing the lowest density of labeled cells, usually at the periphery of the main clusters of labeled cells, have been excluded. Thus, in Figure $5 A-C$, an isodensity surface was chosen that excluded $\sim 15 \%$ of the total number of labeled cells (i.e., excluded the low-density region mainly at the periphery of the main cluster of labeling). This approach emphasizes the 3-D location of the main pontine regions that provide mossy fiber projections to each of the climbing fiber zones under study.

As a result of the exclusion of the lowdensity regions, a central hole appears in the isodensity surface representation of the cells projecting to the A2-face zone (Fig. $5 A$ ). This low-density region is not apparent in the corresponding dot map (Fig. $4 A$ ), because the hole has an oblique orientation and, from the ventral angle of view, is covered by labeled cells located above and below it. With inspection from different angles of view, the centrally located low-density region is readily observed in the dot map.

The different shapes are superimposed in Figure 5D to highlight and assess the spatial relationships between them. As can be seen in Figure 5, $D$ and $J$, the spatial overlap between the three pontine regions was minimal and occurs primarily in areas transitional between them in the rostrocaudal plane. The overlap between pontine regions projecting to the A2face and the $\mathrm{C} 1$-forelimb zones and between the C1-forelimb and C1-hindlimb zone was $\sim 0.2 \%$. No overlap was observed between the pontine regions projecting to the $\mathrm{A} 2$-face and C1-hindlimb zones. For comparison, we also performed a pairwise analysis of the overlap between the cell populations by applying a three-dimensional grid to the data. For each pair of data, we first determined the total number of cubes that contained labeled cells of either category. We then determined the percentage that contained one or more of the two cell categories. This analysis also demonstrated a low degree of overlap. With a grid cube size of $50 \mu \mathrm{m}^{3}$, the overlap percentage was $7.4 \%$ between the A2-face and C1-forelimb cells, 3.5\% between the C1-forelimb and C1-hindlimb cell populations, and $0.7 \%$ between the A2-face and 
C1-hindlimb cell populations. The overlaps were primarily a result of some intermingling of cells in the low-density regions.

Comparison between the spatial distributions of pontocerebellar labeled cells and SI cerebropontine

labeled terminals

The regions occupied by labeled cells in the pontine nuclei obtained in the present experiments as a result of injections of retrograde tracer into different cerebellar cortical zones were also compared with the regions in the pontine nuclei occupied by labeled axonal terminal fields arising from injections of anterograde tracer into SI cortex. The latter results have been published previously (Leergaard et al. 2000a) and were obtained from a data archive available at http://www.nesys.uio.no/Database. A total of five cerebropontine cases were selected from the archive. In case $\mathrm{R} 103$, five individual injections of anterograde tracer were made into the facereceiving area of SI (Fig. $4 B$ ). In cases R115 and R117, a single injection of anterograde tracer was made in each animal into the forelimb-receiving area of SI, and for the present analysis, the results were combined (Fig. 4D). Finally, a single injection of anterograde tracer was made into the hindlimb-receiving area of SI in case R123 and case R124. The results from these two animals have also been combined (Fig. $4 F)$. Each plot in Figure $4, B, D$, and $F$, shows the distribution and relative density of terminal labeling arising from these different injections into SI. The density of points represents an estimate of the number of labeled preterminal fibers within a given pontine region (for additional details of the semiquantitative mapping procedure, see Leergaard et al., 2000a).

Comparison between Figure 4, $A$ and $B$, $C$ and $D$, and $E$ and $F$, reveals a striking similarity between the pontine regions occupied by retrogradely labeled cells and the distribution of anterogradely labeled terminals arising from the corresponding SI-receiving areas. The findings are summarized in Figure 5, in which the isodensity surface map procedure has also been applied to the SI cerebropontine projection data (Fig. $5 E-H$ ). For the SI cerebropontine data (Fig. $5 E-G$ ), tight point clusters representing terminal labeling made it possible to choose an isodensity surface that excluded only $\sim 5 \%$ of the terminal labeling. The results closely match those previously reported by Leergaard et al. (2000a). A visual comparison of the $3-\mathrm{D}$ shapes generated for the pontocerebellar cell distributions with those produced by the SI cerebropontine terminal fields clearly demonstrates similarities between the cell populations and their corresponding SI projections: both in terms of their 3-D shape and location within the contralateral
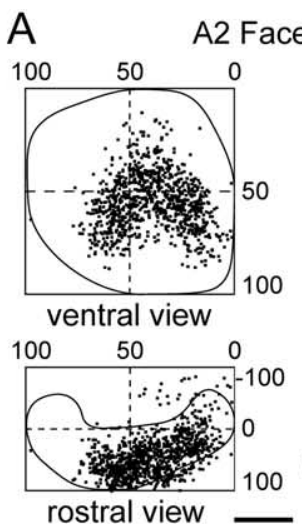

C
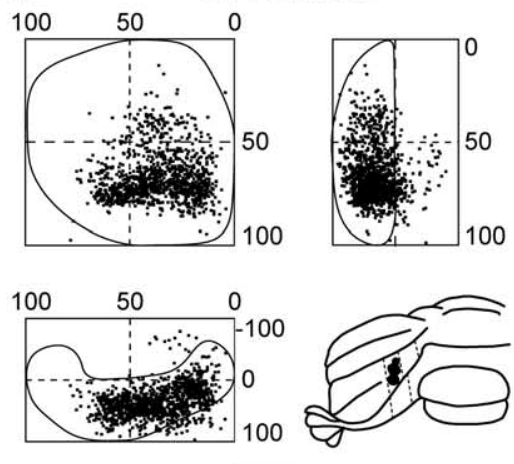

E

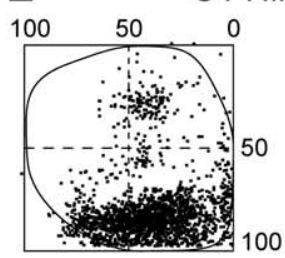

1 Hindlimb
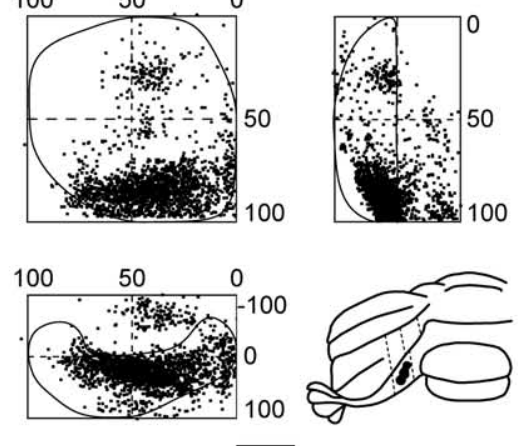
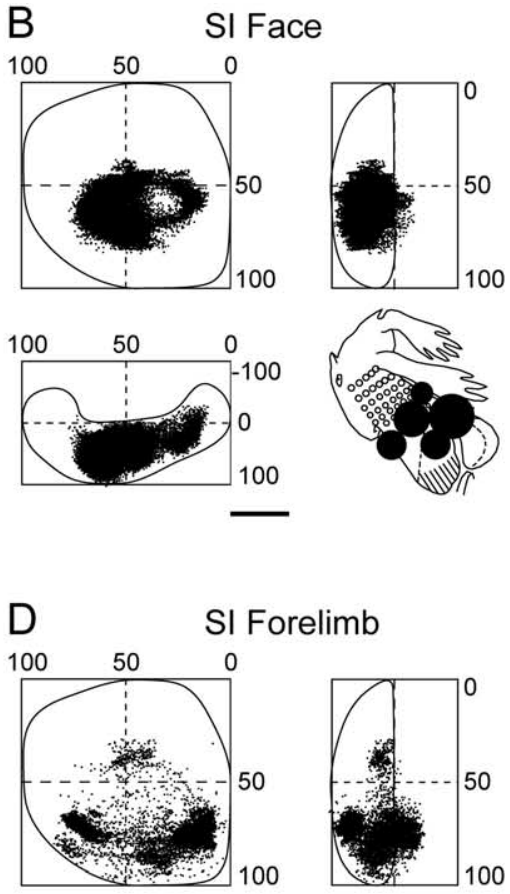

SI Forelimb
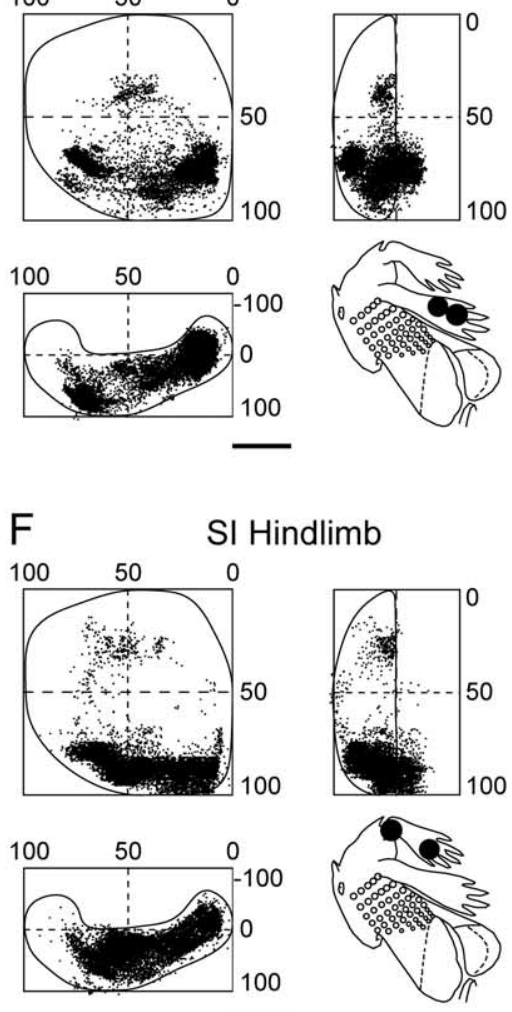

Figure 4. Pontine cell and terminal labeling in pooled cases. $\boldsymbol{A}, \boldsymbol{C}, \boldsymbol{E}$, Standard maps of right pontine nuclei presented in three angles of view showing the spatial distribution of retrogradely labeled cells (dots) after injections of retrograde tracer into three different climbing fiber zones (A2-face, C1-forelimb, and C1-hindlimb zones; $n=3$ cases pooled in each plot). The total extent of combined injection sites is indicated on a posterior view of the left side of the cerebellum. $\boldsymbol{B}, \boldsymbol{D}, \boldsymbol{F}$, Corticopontine axon terminals (fine dots) in right pontine nuclei after injections of anterograde tracer into somatotopically corresponding parts of SI cerebral cortex. Standard somatotopic maps of SI cortex show location of multiple injections in a single case $(\boldsymbol{B})$ and single injections in two cases pooled $(\boldsymbol{D}-\boldsymbol{F})$. Corticopontine data are based on Leergaard et al. (2000a); see http://www.nesys.uio.no/Database. Scale bars, $500 \mu \mathrm{m}$ for pontine maps.

pontine nuclei and in terms of the relative positions of territories associated with different projections. The 3-D shapes are combined in Figure 5, $D$ and $H$. This comparison further emphasizes that all three regions (both in terms of pontine cells and SI axon terminals) occupy mainly nonoverlapping territories within the pontine nuclei, the main differences being that the SI-face and SI-forelimb terminal fields are shifted farther caudal, and that the latter is more extensive in the mediolateral plane than their corresponding pontocerebellar cell populations. 

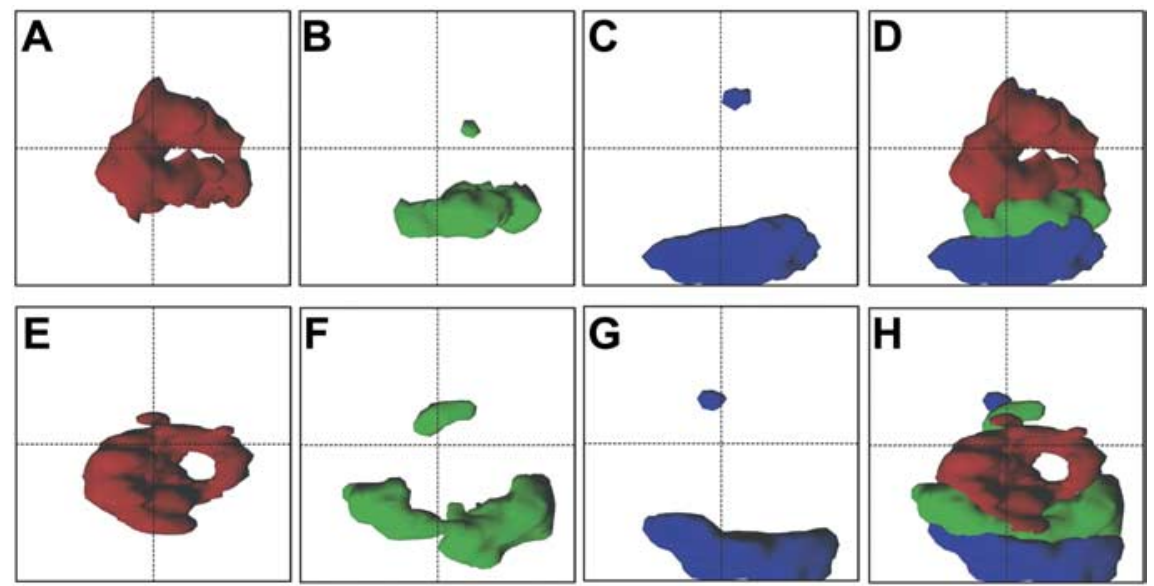

Face

\section{Forelimb}

Hindlimb

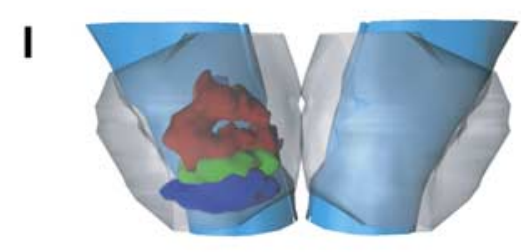

Figure 5. Computer-generated 3-D surface models showing the main location of labeled cells and terminals in the pons. $\boldsymbol{A}-\boldsymbol{D}$, Ventral views of right pontine nuclei showing main territory occupied by cell labeling after injections into three different cerebellar cortical zones defined by the somatotopy of their climbing fiber input ( $\boldsymbol{A}, \mathrm{A2}$-face zone; $\boldsymbol{B}$, C1-forelimb zone; $\boldsymbol{C}, \boldsymbol{C}$-hindlimb zone; $\boldsymbol{D}$, all 3 maps combined). Data from three cases are pooled in each map. $\boldsymbol{E}-\boldsymbol{H}$, Same as $\boldsymbol{A}-\boldsymbol{D}$ but showing main location of axon terminal labeling after injections into somatotopically corresponding parts of SI cortex. Data combined from $n=1(\boldsymbol{E})$ and $n=2$ cases $(\boldsymbol{F}, \boldsymbol{G})$. I, Pontocerebellar cell labeling superimposed onto a ventral view of the caudal brainstem. $\boldsymbol{J}$, Dot map ventral view of all pontocerebellar cell labeling. Note that the central hole apparent in the 3-D surface model shown in $\boldsymbol{A}$ is not visible in the dot map representation (see Results for additional details). Scale bar: (in $\boldsymbol{J}) \boldsymbol{A}-\boldsymbol{H}, \boldsymbol{J}, 500 \mu \mathrm{m}$.

Table 2. Labeled cells and terminals overlap analysis

\begin{tabular}{llll}
\hline & \multicolumn{2}{l}{ Pontine cells } & \\
\cline { 2 - 4 } Axon terminals & A2-face & C1-forelimb & C1-hindlimb \\
\hline SI-face & $4.7 \%$ & $11.2 \%$ & $0.6 \%$ \\
SI-forelimb & $0.6 \%$ & $6.2 \%$ & $6.9 \%$ \\
SI-hindlimb & $0.6 \%$ & $0.1 \%$ & $11.4 \%$ \\
\hline
\end{tabular}

Overlap expressed as a percentage of the total volume of the pontine nuclei occupied by labeled pontocerebellar cells projecting to a given climbing fiber zone.

Table 3. Labeled cells and terminals overlap analysis

\begin{tabular}{llll}
\hline & \multicolumn{2}{l}{ Axon terminals } & \\
\cline { 2 - 4 } Pontine cells & SI-face & SI-forelimb & SI-hindlimb \\
\hline A2-face & $5.3 \%$ & $1.1 \%$ & $0.09 \%$ \\
C1-forelimb & $2.6 \%$ & $4.0 \%$ & $0.07 \%$ \\
C1-hindlimb & $0.4 \%$ & $7.0 \%$ & $9.3 \%$ \\
\hline
\end{tabular}

Overlap expressed as a percentage of the total volume of the pontine nuclei occupied by terminals arising from a given somatotopical area of SI cerebral cortex.

Although caution is necessary when comparing at the light microscope level nuclear regions occupied by anterogradely labeled terminals and those occupied by retrogradely labeled cells, a more quantitative analysis showed that despite a clear similarity in spatial organization, nonetheless, there were only modest overlaps between the 3-D volumes in the pons occupied by labeled terminals and cells. Expressed as a volume percentage of each of the 3-D shapes, the overlaps ranged from 0.07 to $11.4 \%$ (Tables 2, 3). Overall, the greatest overlaps were usually observed between somatotopically corresponding regions (e.g., SIhindlimb terminals and cells projecting to the C1-hindlimb zone,
SI-face terminals, and cells projecting to the A2-face zone). The exceptions were regions occupied by cells targeting the $\mathrm{C} 1$ forelimb or C1-hindlimb zones, which demonstrated, respectively, a greater overlap with terminals arising from SI-face and SI-forelimb parts of the cerebral cortex (Table 2).

Studying the 3-D shapes from different angles of view reveals the reason for the limited overlaps between somatotopically equivalent cell and terminal regions. SI axon terminals do not intermingle with the corresponding cells but instead form a shell that surrounds them. Axon terminals from both SI-forelimb and SI-hindlimb have a caudodorsal approach toward their respective cells projecting to the $\mathrm{C} 1$ forelimb and C1-hindlimb zones. The SIface terminals, on the other hand, come in from a dorsolateral aspect toward cells projecting to the A2-face zone (see http:// www.nesys.uio.no/Database). Also evident is some overlap between the SI-face terminal projection territory and the $\mathrm{C} 1$ forelimb zone cell territory. The SI-face axon terminals mainly overlap with the lateral aspect of the cell cluster projecting to the $\mathrm{C} 1$-forelimb zone (the overlap was $11.2 \%$ of the cell region targeting the $\mathrm{C} 1$ forelimb zone and $2.65 \%$ of the SI-face terminal region).

In summary, the present experiments provide evidence that clear topographical differences exist between the locations of cells of origin of pontocerebellar mossy fiber projections to the climbing fiber-defined A2-face, C1-forelimb, and C1-hindlimb cortical zones in the posterior lobe of the rat cerebellum. This topography is remarkably similar (but not identical) to the spatial localization of axon terminals in the pontine nuclei arising from somatopically equivalent parts of the SI cerebral cortex.

\section{Discussion}

In the present study, we mapped the distribution of pontine cells projecting to the climbing fiber-defined A2-face, C1-forelimb, and $\mathrm{C} 1$-hindlimb cortical zones in the posterior lobe of the rat cerebellum. Together, the three cell groups were distributed in one main cluster, but a clear topographical organization was found with the cell group projecting to the A2-face zone occupying the central region of the pontine nuclei, whereas the cell groups projecting to the $\mathrm{C} 1$-forelimb and $\mathrm{C} 1$-hindlimb zones were found to occupy progressively more caudal regions. The three cell groups were complementary in shape with very little or no overlap between them. They also displayed a close similarity to the spatial distribution of cerebropontine terminal fibers arising from somatotopically homologous parts of SI cerebral cortex.

\section{Methodological considerations}

One possible complication is that the degree of segregation of climbing fiber inputs observed in the anesthetized animal is a feature of the anesthetic used and is not present in the awake animal. However, there are two lines of evidence to suggest that this is unlikely to be the case. First, in the present experiments, no 
differences were observed in zonal organization in pentobarbitonecompared with propofol-anesthetized rats. Second, studies in which mapping of cerebellar cortical zones in the barbiturate- or propofolanesthetized cat have been used to guide the insertion of recording microwires into the cerebellar cortex have found that the climbing fiber responses obtained from individual microwires in the awake animal displayed the same pattern of peripheral input as the zone in which they were implanted (Pardoe et al., 2004). Together, these findings suggest that the cerebellar cortical territory in which particular climbing fiber responses occur is not constrained by the choice of anesthetic and that the degree of segregation of climbing fiber inputs is maintained in the awake animal.

\section{Topographic patterns in the pontine nuclei}

The topographical arrangement of pontocerebellar projections was consistent with the organizational scheme described originally by Leergaard et al. (1995) for the development of cerebropontine projections in neonate rats and also for the spatial pattern of cerebropontine terminations in adult rat, cat, and monkey (for reviews and references, see Brodal and Bjaalie, 1997; Schmahmann and Pandya, 1997). Injections into the A2-face, C1-forelimb, and C1-hindlimb cerebellar cortical zones resulted, respectively, in cell labeling located in approximately concentric internal to external shells (lamellas) within the pontine nuclei, with virtually no intermingling of cells projecting to different cerebellar targets. In double-tracer experiments, no doublelabeled cells were found.

If the precise pontocerebellar topography defined by olivocerebellar somatotopy described in the present experiments for paravermal/vermal parts of the posterior lobe of the rat cerebellum is to be regarded as a general principle of organization, then it is important to consider other regions of cerebellar cortex. By comparison to the pontocerebellar projection to the C1-forelimb zone in the paramedian lobule, the pontocerebellar projection to the same zone but in lobulus simplex has been shown to have a very similar spatial organization (Herrero et al., 2002). Also, injections of retrograde tracer into hemispheral crus IIa, in an area corresponding to zebrin band P5b + (and thus cortical zone C2) (cf. Voogd et al., 2003), and where granular layer responses were evoked by upper lip stimulation (Lillehaug et al., 2004), produced a near identical pattern of pontine cell labeling as detailed in the present experiments but for injections centered on the vermal A2-face zone. Together, these results therefore strongly suggest that the principle of organization proposed in the present experiments may also apply to other parts of the rat cerebellar cortex.

Three-dimensional analyses also showed that the spatial distribution of the pontocerebellar neurons closely resembled the pattern of termination of cerebropontine projections arising from somatotopically corresponding parts of SI (cf., Leergaard et al., 2000a,b). This suggests that body map representations may be preserved in the link between cerebral cortex and pontine cells. Consistent with this possibility is the finding that trigeminocerebellar inputs to crus II appear to be in register with SIpontocerebellar inputs from corresponding face representations (Bower et al., 1981; Woolston et al. 1981). However, somatotopic correspondence with other pathways (e.g., between pontocerebellar and spinocerebellar systems) is not known.

Preservation of somatotopical relationships does not, however, exclude opportunities for new map properties in the pontine nuclei, not present in the cerebral cortex. For example, by comparison with the two-dimensional SI map, our results show that within the pontine map, the hindlimb region has a much larger interface and closer proximity with the forelimb region, which in turn has the same association with the face region (Fig. $5 D, H)$. Our analysis also demonstrated a partial overlap between SI-face terminal fields and pontine cells projection to the C1forelimb zone, suggesting in this case an opportunity for integration of information across body parts.

Nevertheless, it is important to emphasize that in the present study, it was only possible to chart the spatial location of cell bodies retrogradely labeled with tracer. The long dendritic arbor of pontine projection neurons probably means they are able to receive synaptic inputs across more than one region of pons receiving cerebropontine terminals from different parts of SI (cf. Mihailoff et al., 1981; Brodal and Bjaalie, 1992). Furthermore, cerebropontine projections have been shown to target mainly distal dendrites of pontine cells (Hollander et al., 1968; Mihailoff and McArdle 1981; Brodal and Bjaalie, 1992). Thus, the absence of spatial overlaps between terminals and cells does not necessarily indicate the absence of functional interactions (and vice versa). Detailed electrophysiological studies of cerebral inputs to identified pontocerebellar projection neurons together with ultrastructural studies would be required to confirm any functional linkage.

\section{From continuous cerebral to fractured cerebellar somatotopy}

Unlike the SI cortex, which has a relatively continuous somatotopic map (Woolsey, 1958; Welker, 1971; Chapin and Lin, 1990), granule cells and mossy fibers in the cerebellar granular layer have peripheral receptive fields that together form a highly discontinuous representation of the body surface, sometimes referred to as a fractured map (Shambes et al., 1978; Bower et al., 1981; Welker, 1987; Bower and Kassel, 1990). Electrophysiological data have suggested that a highly specific projection pattern exists between the SI cortex and the cerebellar granule cell layer (Bower et al., 1981). However, the exact nature of the transformation from the continuous cerebral map to the discontinuous cerebellar map remains an issue of contention.

The segregated and clustered organization of cerebropontine projections observed in previous anatomical studies (Wiesendanger and Wiesendanger, 1982; Mihailoff et al., 1985; Panto et al., 1995) implies that there may be changes in neighboring relationships in the SI-pontine projection map. This is viewed by some as the origin of the fractured cerebellar map (Schwarz and Thier, 1995, 1999; Schwarz and Mock, 2001). However, other studies have shown that neighboring relationships may be preserved in the SI-pontine projection, suggesting instead that the fractured cerebellar map arises in the second link, the pontocerebellar projection (Leergaard et al., 2000a,b). Several studies have shown that pontocerebellar mossy fibers are highly collateralized (Mihailoff, 1983; Shinoda et al., 1992; Bjaalie and Brodal, 1997; Voogd et al., 2003), and physiological data indicate that mossy fiber collateralization underlies the fractured organization of the trigeminocerebellar projection (Woolston et al., 1981). Other data in rats that support the notion of fractured cerebellar maps created by such branching are that (1) pontine cells seem to have small peripheral receptive fields (Eycken et al., 2000; Rajan et al., 2000), and (2) pontine cells projecting to single body representations in the posterior cerebellum are distributed across the entire region of the pontine nuclei receiving inputs from SI cortex (present study). Although a matter of contention, it remains a possibility that the mossy fiber-granule cell-parallel fiber system also contributes to the generation of the fractured cerebellar map.

\section{Concluding comments}

The use of a combination of electrophysiological mapping, neuronatomical tract tracing and $3-\mathrm{D}$ reconstruction, and image 
analysis techniques have shown that a highly specific topography exists within cerebropontocerebellar projections that converge in the cerebellar cortex with corresponding peripheral inputs relayed by the climbing fiber system. This suggests that functionally related information is conveyed to the same part of the cerebellar cortex via direct (olivocerebellar) and indirect (cerebropontocerebellar) pathways. This convergence may contribute to the similarity of peripheral receptive fields between climbing fibers and mossy fibers terminating in the same vertical "column" of cerebellar cortex (Eccles et al., 1968; Ekerot and Larson, 1980; Garwicz et al., 1998; Brown and Bower, 2001).

The convergence of somatosensory information via direct and indirect routes is also likely to have an important influence on cerebellar cortical processing. For example, tactile information arising from the face is forwarded to the cerebellar A2 zone by the climbing fiber system with an onset latency of $\sim 17 \mathrm{~ms}$ (Atkins and Apps, 1997), whereas the indirect path via the somatosensory cortex and the pontocerebellar mossy fiber projection is likely to reach the same region of cerebellar cortex around the same time (Morissette and Bower, 1996). The direct (climbing fibermediated) and indirect (mossy fiber-mediated) signals arriving in register are likely to have a profound influence on ongoing cerebellar cortical activity. One of the challenges for future studies will be to identify how bringing these two types of information together modifies corticofugal outflow during behavior.

\section{References}

Apps R (1990) Columnar organisation of the inferior olive projection to the posterior lobe of the rat cerebellum. J Comp Neurol 302:236-254.

Apps R, Garwicz M (2005) Anatomical and physiological foundations of cerebellar information processing. Nat Rev Neurosci 6:297-311.

Ashburner J, Friston KJ (1999) Spatial normalization. In: Brain warping (Toga AW, ed), pp 27-44. San Diego: Academic.

Atkins MJ, Apps R (1997) Somatotopical organisation within the climbing fibre projection to the paramedian lobule and copula pyramidis of the rat cerebellum. J Comp Neurol 389:249-263.

Bjaalie JG, Brodal P (1997) Cat pontocerebellar network: numerical capacity and axonal collateral branching of neurones in the pontine nuclei projecting to individual parafloccular folia. Neurosci Res 27:199-210.

Bower JM, Kassel J (1990) Variability in tactile projection patterns to cerebellar folia crus IIA of the Norway rat. J Comp Neurol 302:768-778.

Bower JM, Beermann DH, Gibson JM, Shambes GM, Welker W (1981) Principles of organization of a cerebro-cerebellar circuit. Micromapping the projections from cerebral (SI) to cerebellar (granule cell layer) tactile areas of rats. Brain Behav Evol 18:1-18.

Brevik A, Leergaard TB, Svanevik M, Bjaalie JG (2001) Three-dimensional computerised atlas of the rat brain stem precerebellar system: approaches for mapping, visualization, and comparison of spatial distribution data. Anat Embryol (Berl) 204:319-332.

Brodal P, Bjaalie JG (1992) Organization of the pontine nuclei. Neurosci Res 13:83-118.

Brodal P, Bjaalie JG (1997) Salient anatomic features of the cortico-pontocerebellar pathway. Prog Brain Res 114:227-249.

Brown IE, Bower JM (2001) Congruence of mossy fiber and climbing fiber tactile projections in the lateral hemispheres of the rat cerebellum. J Comp Neurol 429:59-70.

Chapin JK, Lin CS (1990) The somatic sensory cortex of the rat. In: The cerebral cortex of the rat (Kolb B, Tees RC, eds), pp 341-380. Cambridge, MA: MIT.

Eccles JC, Provini L, Strata P, Taborikova H (1968) Analysis of electrical potentials evoked in the cerebellar anterior lobe by stimulation of hindlimb and forelimb nerves. Exp Brain Res 6:171-194.

Ekerot CF, Larson B (1980) Termination in overlapping sagittal zones in cerebellar anterior lobe of mossy and climbing fiber paths activated from dorsal funiculus. Exp Brain Res 38:163-172.

Eycken A, Bjaalie JG, Volny-Luraghi A, De Schutter E (2000) Electrophysiological study of the rat pontine nuclei. Eur J Neurosci Abstr 11:189.09.

Garwicz M, Jorntell H, Ekerot CF (1998) Cutaneous receptive fields and topography of mossy fibres and climbing fibres projecting to cat cerebellar C3 zone. J Physiol (Lond) 512: 277-293.

Herrero L, Pardoe J, Apps R (2002) Pontine and lateral reticular projections to the $c_{1}$ zone in lobulus simplex and paramedian lobule of the rat cerebellar cortex. Cerebellum 1:185-199.

Hollander H, Brodal P, Walberg F (1968) Electronmicroscopic observations on the structure of the pontine nuclei and the mode of termination of the corticopontine fibres. An experimental study in the cat. Exp Brain Res 7:95-110.

King VM, Armstrong DM, Apps R, Trott JR (1998) Numerical aspects of pontine, lateral reticular, and inferior olivary projections to two paravermal cortical zones of the cat cerebellum. J Comp Neurol 390:537-551.

Leergaard TB (2003) Clustered and laminar topographic patterns in rat cerebro-pontine pathways. Anat Embryol (Berl) 206:149-162.

Leergaard TB, Lakke EA, Bjaalie JG (1995) Topographical organization in the early postnatal corticopontine projection: a carbocyanine dye and 3-D computer reconstruction study in the rat. J Comp Neurol 361:77-94.

Leergaard TB, Lyngstad KA, Thompson JH, Taeymans S, Vos BP, De Schutter E, Bower JM, Bjaalie JG (2000a) Rat somatosensory cerebropontocerebellar pathways: spatial relationships of the somatotopic map of the primary somatosensory cortex are preserved in a three-dimensional clustered pontine map. J Comp Neurol 422:246-266.

Leergaard TB, Alloway KD, Mutic JJ, Bjaalie JG (2000b) Three-dimensional topography of corticopontine projections from rat barrel cortex: correlations with corticostriatal organization. J Neurosci 20:8474-8484.

Lillehaug S, Leergaard TB, De Schutter E, Bower JM, Bjaalie JG (2004) Ponto-cerebellar projections to electrophysiologically defined patches in the granule cell layer of rat Crus IIa. FENS Abstr 2:A129.8.

Mihailoff GA (1983) Intra- and interhemispheric collateral branching in the rat pontocerebellar system, a fluorescence double-label study. Neuroscience 10:141-160.

Mihailoff GA, McArdle CB (1981) The cytoarchitecture, cytology, and synaptic organization of the basilar pontine nuclei in the rat. II. Electron microscopic studies. J Comp Neurol 195:203-219.

Mihailoff GA, McArdle CB, Adams CE (1981) The cytoarchitecture, cytology, and synaptic organization of the basilar pontine nuclei in the rat. I. Nissl and Golgi studies. J Comp Neurol 195:181-201.

Mihailoff GA, Lee H, Watt CB, Yates R (1985) Projections to the basilar pontine nuclei from face sensory and motor regions of the cerebral cortex in the rat. J Comp Neurol 237:251-263.

Morissette J, Bower JM (1996) Contribution of somatosensory cortex to responses in the rat cerebellar granule cell layer following peripheral tactile stimulation. Exp Brain Res 109:240-250.

Panto MR, Cicirata F, Angaut P, Parenti R, Serapide F (1995) The projection from the primary motor and somatic sensory cortex to the basilar pontine nuclei. A detailed electrophysiological and anatomical study in the rat. J Hirnforsch 36:7-19.

Pardoe J, Apps R (2002) Structure-function relations of two somatotopically corresponding regions of the rat cerebellar cortex: olivo-corticonuclear connections. Cerebellum 1:165-184.

Pardoe J, Edgley SA, Drew T, Apps R (2004) Changes in excitability of ascending and descending inputs to cerebellar climbing fibers during locomotion. J Neurosci 24:2656-2666.

Rajan R, Cerminara NL, Rawson JA (2000) Response properties of pontine projections to the cerebellum in the rat. Soc Neurosci Abstr 26:742.8.

Schmahmann JD, Pandya DN (1997) The cerebrocerebellar system. Int Rev Neurobiol 41:31-60.

Schwarz C, Mock M (2001) Spatial arrangement of cerebro-pontine terminals. J Comp Neurol 435:418-432.

Schwarz C, Thier P (1995) Modular organization of the pontine nuclei: dendritic fields of identified pontine projection neurons in the rat respect the borders of cortical afferent fields. J Neurosci 15:3475-3489.

Schwarz C, Thier P (1999) Binding of signals relevant for action: towards a hypothesis of the functional role of the pontine nuclei. Trends Neurosci 22:443-451.

Shambes GM, Gibson JM, Welker W (1978) Fractured somatotopy in granule cell tactile areas of rat cerebellar hemispheres revealed by micromapping. Brain Behav Evol 15:94-140.

Shinoda Y, Sugiuchi Y, Futami T, Izawa R (1992) Axon collaterals of mossy fibers from the pontine nucleus in the cerebellar dentate nucleus. J Neurophysiol 67:547-560.

Teune TM, van der Burg J, De Zeeuw CI, Voogd J, Ruigrok TJ (1998) Single Purkinje cell can innervate multiple classes of projection neurons in the 
cerebellar nuclei of the rat: a light microscopic and ultrastructural tripletracer study in the rat. J Comp Neurol 392:164-178.

Voogd J, Glickstein M (1998) The anatomy of the cerebellum. Trends Neurosci 21:370-375.

Voogd J, Pardoe J, Ruigrok TJ, Apps R (2003) The distribution of climbing and mossy fiber collateral branches from the copula pyramidis and the paramedian lobule: congruence of climbing fiber cortical zones and the pattern of zebrin banding within the rat cerebellum. J Neurosci 23:4645-4656.

Welker C (1971) Microelectrode delineation of fine grain somatotopic organization of $(\mathrm{SmI})$ cerebral neocortex in albino rat. Brain Res $26: 259-275$.
Welker W (1987) Spatial organization of somatosensory projections to granule cell cerebellar cortex: functional and connectional implications of fractured somatotopy (summary of Wisconsin studies). In: New concepts in cerebellar neurobiology (King JS, ed), pp 239-280. New York: Liss.

Wiesendanger R, Wiesendanger M (1982) The corticopontine system in the rat. II. The projection pattern. J Comp Neurol 208:227-238.

Woolsey CN (1958) Organization of somatic sensory and motor areas of the cerebral cortex. In: Biological and biochemical bases of behaviour (Harlow HF, Woolsey CN, eds), pp 63-81. Madison, WI: University of Wisconsin.

Woolston DC, Kassel J, Gibson JM (1981) Trigeminocerebellar mossy fiber branching to granule cell layer patches in the rat cerebellum. Brain Res 209:255-269. 